\title{
Inhibitory effect of sodium houttuyfonate on synovial proliferation in vitro in cells from a patient with rheumatoid arthritis
}

\author{
JUN LI $^{1}$, TING ZHOU ${ }^{2}$ and FUTAO ZHAO ${ }^{1}$ \\ ${ }^{1}$ Department of Rheumatology and Immunology, Shanghai Third People's Hospital, School of Medicine, \\ Shanghai Jiao Tong University, Shanghai 201999; ${ }^{2}$ Department of Rheumatology and Immunology, \\ Huainan First People's Hospital, Huainan, Anhui 232000, P.R. China
}

Received November 28, 2013; Accepted March 11, 2014

DOI: $10.3892 / \mathrm{etm} .2014 .1636$

\begin{abstract}
The aim of the present study was to investigate the inhibitory effect of sodium houttuyfonate (SH) on synovial cell proliferation in vitro. Primary cells were obtained from the synovial tissue of a patient with rheumatoid arthritis (RA). The cells were divided into five treatment groups as follows: the control group (group 1), $25 \mu \mathrm{g} / \mathrm{ml} \mathrm{SH-treated} \mathrm{group}$ (group 2), $50 \mu \mathrm{g} / \mathrm{ml} \mathrm{SH-treated} \mathrm{group} \mathrm{(group} \mathrm{3),} 100 \mu \mathrm{g} / \mathrm{ml}$ SH-treated group (group 4) and the $200 \mu \mathrm{g} / \mathrm{ml} \mathrm{SH}$-treated group (group 5). Following seven days of treatment, the proliferation rate of the synovial cells was then detected using an MTT assay. The expression level of proliferative synovial cells markedly decreased in the SH-treated groups in a dose-dependent manner compared with the control group. In conclusion, the present study demonstrated that SH was able to inhibit the proliferation of synovial cells obtained from a patient with RA. These results provide a potential theoretical basis for the development of a safe and effective treatment against RA in the future.
\end{abstract}

\section{Introduction}

Rheumatoid arthritis (RA) is the most common type of inflammatory arthritis, affecting between 0.5 and $1 \%$ of the population worldwide, regardless of geographical location and ethnicity $(1,2)$. Although the etiology of RA remains to be fully elucidated, numerous studies have suggested that a combination of environmental and genetic factors are responsible. However, although environmental and genetic factors have been demonstrated to be important, they are insufficient for full expression of the disease. The primary inflammatory site

Correspondence to: Dr Futao Zhao, Department of Rheumatology and Immunology, Shanghai Third People's Hospital, School of Medicine, Shanghai Jiao Tong University, 280 Mohe Road, Baoshan, Shanghai 201999, P.R.China

E-mail: zhaofutao@aliyun.com

Key words: rheumatoid arthritis, sodium houttuyfonate, synovial proliferation, MTT assay in RA is the synovium. The proliferation of synovial fibroblasts is one of the main characteristics of RA and is considered to be necessary for the initiation and long-term progression of joint destruction in RA (3-6). In the long-term, joint destruction may lead to limited functions, decreased work ability and, more importantly, a decrease in the quality of life for patients with RA. In addition, RA is associated with an increased risk of cardiovascular disease and, thus, the life expectancy of patients with RA may be reduced by 3-18 years (7). Therefore, the inhibition of synovial hyperplasia during the early stages of disease progression may provide a potential therapeutic approach for the treatment of RA.

Houttuynia cordata Thunb (HCT) is a perennial herbaceous plant that grows in the wild in moist, shady areas in numerous Asian countries, including India. HCT has been widely used in China, Japan and other Asian countries as a medicine due to its anti-inflammatory properties (8). Previous studies have demonstrated that HCT has anti-inflammatory effects in a wide range of diseases (8-11). During the outbreak of hand, foot and mouth disease (HFMD) in 2008 in China, HCT was used as a therapeutic drug (12). Several studies demonstrated that HCT inhibited enterovirus 71 and coxsackievirus A16, which are the two main causative agents of HFMD $(13,14)$. It has also been demonstrated that HCT water extract was able to treat severe acute respiratory syndrome $(8,15,16)$ and herpes simplex virus infection (17). Sodium houttuyfonate (SH), an addition compound of sodium bisulfite and houttuynia, is the stable form of houttuynia and exhibits the same effect as HCT. Certain studies have demonstrated that SH has an antibacterial effect against 21 strains of Staphylococcus aureus (18) and it has previously been used for the treatment of cationic bovine serum albumin-induced membranous glomerulonephritis in BALB/c mice (19). Previous studies have also demonstrated that SH exerts an anti-inflammatory effect by inhibiting the tumor necrosis factor- $\alpha$ (TNF- $\alpha$ ) pathway (20), which led to the hypothesis that SH may also be effective for the treatment of RA.

\section{Materials and methods}

Materials. Synovial tissue was obtained from a patient at the Department of Orthopedics and Pathology, Shanghai Third People's Hospital (Shanghai, China). SH was purchased from 
Shanghai Qingping Pharmaceutical Co., Ltd. (Shanghai, China; batch number 0701-3). D-Hank's solution and RPMI-1640 nutrient medium were provided by the laboratory of the Shanghai Third People's Hospital, School of Medicine, Shanghai Jiao Tong University (Shanghai, China). Fetal bovine serum (FBS) was purchased from Beijing Ruizekang Biotech Co., Ltd. (Beijing, China). Type II collagenase and trypsin were obtained from Shanghai Qifa Experimental Reagent Co., Ltd. (Shanghai, China). The MTT kit was purchased from Sigma (St. Louis, MO, USA). Informed consent was obtained from the patient.

Cultivation of primary cells from a patient with $R A$. The fat and fibrous tissue was removed from the synovial tissue. The tissue was then washed three times with D-Hank's solution and cut into two sections (1-2 $\mathrm{mm}$ in size). The tissue was placed in $25 \mathrm{~cm}^{2}$ culture bottles containing $2 \mathrm{ml}$ RPMI-1640 nutrient solution in 10\% FBS and $2 \mathrm{ml} 0.4 \%$ type II collagenase. The culture bottles were incubated at $37^{\circ} \mathrm{C}$ and $5 \% \mathrm{CO}_{2}$ for $2 \mathrm{~h}$. Unattached cells were then transferred into centrifuge tubes and centrifuged for $10 \mathrm{~min}$. A total of $4 \mathrm{ml} 0.25 \%$ trypsin was added and the cells were incubated for $30 \mathrm{~min}$. The solution was then filtered using a 200-mesh nylon net. Following centrifugation for $10 \mathrm{~min}$, the cells were incubated as aforementioned for $24 \mathrm{~h}$. The unattached cells were discarded, leaving primary cells from a patient with RA (Fig. 1).

Experimental groups and administration. The primary cells were equally divided into five groups as follows: the control group (group 1), cells treated with $25 \mu \mathrm{g} / \mathrm{ml} \mathrm{SH}$ (group 2), $50 \mu \mathrm{g} / \mathrm{ml} \mathrm{SH}$ (group 3), $100 \mu \mathrm{g} / \mathrm{ml} \mathrm{SH}$ (group 4) and $200 \mu \mathrm{g} / \mathrm{ml}$ SH (group 5). Group 1 was administered an equivalent amount of normal saline (NS), whilst groups 2 to 5 were treated with corresponding amounts of SH. NS and SH were administered daily for 7 days by transfer pipette. Following the final administration, the five groups of synovial cells were measured using an MTT assay for analysis of the growth inhibitory rate of SH on synovial proliferation.

MTT assay. Sequential dilutions of cells in the culture medium between $10^{6}$ and $10^{3}$ cells $/ \mathrm{ml}$ were prepared. A total of $100 \mu \mathrm{l}$ each dilution was analyzed in triplicate, using a microplate reader (Bio-Rad, Hercules, CA, USA) and three control wells containing medium only were used as an absorbance reference. The cells were then incubated for $24 \mathrm{~h}$. A total of $10 \mu \mathrm{l}$ MTT reagent $(0.25 \%$ MTT) was added to each well and the cells were further incubated for $4 \mathrm{~h}$ until a purple precipitate was observed. A total of $100 \mu \mathrm{l}$ detergent reagent was added to each well and swirled gently, and the plate was then incubated in the dark overnight at room temperature. The absorbance in each well at $570 \mathrm{~nm}$ was measured using a microplate reader. Finally, the data were recorded and the results were analyzed.

Data interpretation and statistical analysis. If the absorbance rate was lower than the control, this was considered to indicate a reduction in cell proliferation. By contrast, if the absorbance rate was higher, this indicated an increase in cell proliferation. The difference in the inhibition rate between the groups was analyzed using one-way analysis of covariance. $\mathrm{P}<0.05$ was considered to indicate a statistically significant difference.
Table I. Association between the inhibition rate of sodium houttuyfonate and its concentration. The correlative coefficient is 0.961718 .

\begin{tabular}{lc}
\hline Inhibition rate $(\%)$ & Concentration $(\mu \mathrm{g} / \mathrm{ml})$ \\
\hline 17.02 & 25 \\
38.30 & 50 \\
54.79 & 100 \\
76.60 & 200 \\
\hline
\end{tabular}

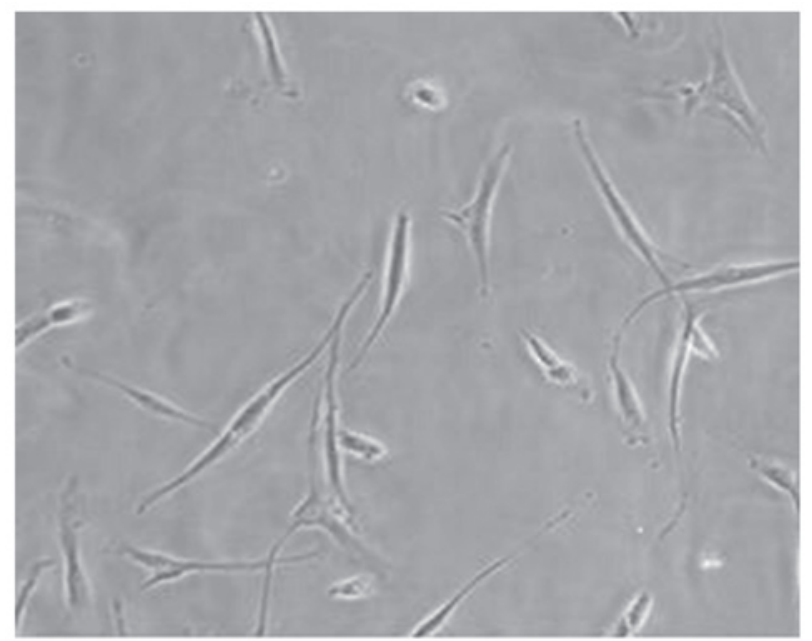

Figure 1. Primary synovial cells obtained from a patient with rheumatoid arthritis (magnification, $\mathrm{x} 100$ ).

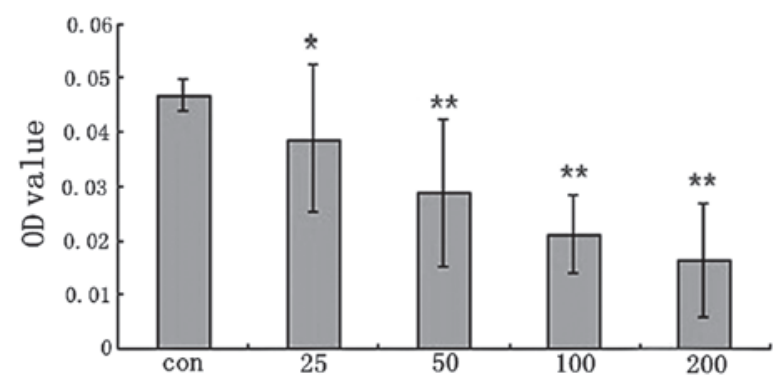

Figure 2. Inhibitory effect of SH on the proliferation of synovial cells from a patient with rheumatoid arthritis. The cells were treated with 25, 50, 100 and $200 \mu \mathrm{g} / \mathrm{ml} \mathrm{SH}$. ${ }^{*} \mathrm{P}<0.05$ and ${ }^{* *} \mathrm{P}<0.01$ versus con. OD, optical density; con, control; $\mathrm{SH}$, sodium houttuyfonate.

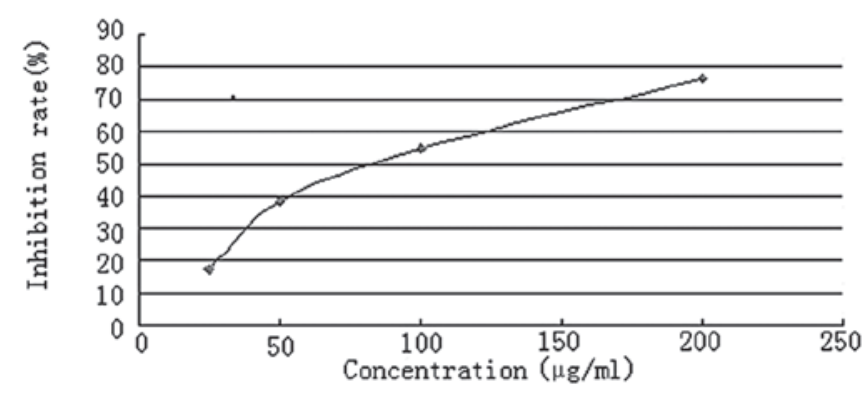

Figure 3. Inhibition rate of different concentrations of sodium houttuyfonate. 


\section{Results}

Inhibition rate of $\mathrm{SH}$ on synovial proliferation in cells from a patient with RA. As shown in Fig. 2, the proliferation rate of synovial cells was markedly higher in the control group compared with the other groups $(\mathrm{P}<0.05)$. In the SH-treated groups, the proliferation rates of synovial cells were significantly decreased compared with those in group $1(\mathrm{P}<0.05$ for group 2; $\mathrm{P}<0.01$ for groups 3-5). These results indicated that $\mathrm{SH}$ decreased the level of synovial proliferation in cells from a patient with RA. Fig. 3 shows the inhibition rate of different concentrations of $\mathrm{SH}$ on synovial proliferation. The inhibition rates of different concentrations of SH are shown numerically in Table I and the correlation coefficient was found to be 0.961718 .

\section{Discussion}

The proliferation of synovial fibroblasts leads to the development of RA and initiates joint destruction in the long term (3-5). Previous studies have demonstrated that TNF- $\alpha$, interleukin (IL)-6 and IL- 8 are important proinflammatory cytokines in the pathogenesis of RA (21-24), and that the inhibition of TNF- $\alpha$ and IL-6 is effective in the treatment of patients with RA (25-27). Notably, several studies have indicated that HCT was able to efficiently inhibit IL-6, IL-8 and TNF- $\alpha(24,28)$. In addition, nonsteroidal anti-inflammatory drugs (NSAIDs) have been demonstrated to be efficacious in the treatment of RA by binding to cyclooxygenase (COX) enzymes and therefore inhibiting the production of prostaglandins. Previous studies also demonstrated that HCT supercritical extract exerted an anti-inflammatory effect by inhibiting the COX-2/prostaglandin E2 pathway. Owing to the gastrointestinal side-effects of NSAIDs, HCT may be a better drug candidate for the alleviation of symptoms caused by RA (20). The present study demonstrated that the synovial proliferation rate significantly decreased following treatment with SH. Furthermore, the inhibition rate of SH was found to be dose dependent. Therefore, these results suggest that $\mathrm{SH}$ is able to inhibit the proliferation of synovial cells from a patient with RA.

The results from the present study provide a potential theoretical basis for the treatment of RA. Furthermore, due to the dose-dependent reaction of SH observed in the present study, a suitable dose of SH may almost completely inhibit synovial proliferation and therefore be highly effective in the clinical treatment of patients with RA.

\section{Acknowledgements}

The authors would like to thank the doctors at the Department of Orthopedics and Pathology, as well as the technicians at the laboratory of Shanghai Third People's Hospital, School of Medicine, Shanghai Jiao Tong University for their technical assistance.

\section{References}

1. Gabriel SE and Michaud K: Epidemiological studies in incidence, prevalence, mortality, and comorbidity of the rheumatic diseases. Arthritis Res Ther 11: 229, 2009.
2. Yilmaz S and Simek I: Early intervention in the treatment of rheumatoid arthritis: focus on tocilizumab. Ther Clin Risk Manag 9: 403-408, 2013.

3. Mor A, Abramson SB and Pillinger MH: The fibroblast-like synovial cell in rheumatoid arthritis: a key player in inflammation and joint destruction. Clin Immunol 115: 118-128, 2005.

4. Huber LC, Distler O, Tarner I, Gay RE, Gay S and Pap T: Synovial fibroblasts: key players in rheumatoid arthritis. Rheumatology (Oxford) 45: 669-675, 2006.

5. Bartok B and Firestein GS: Fibroblast-like synoviocytes: key effector cells in rheumatoid arthritis. Immunol Rev 233: 233-255, 2010.

6. Parada-Turska J, Nowicka-Stażka P, Majdan M, Jabłoński M, Turski WA and Rzeski W: Anti-epileptic drugs inhibit viability of synoviocytes in vitro. Ann Agric Environ Med 20: 571-574, 2013.

7. Pincus T, Kavanaugh A and Sokka T: Benefit/risk of therapies for rheumatoid arthritis: underestimation of the 'side effects' or risks of RA leads to underestimation of the benefit/risk of therapies. Clin Exp Rheumatol 22 (Suppl 35): S2-S11, 2004.

8. Lu HM, Liang YZ, Yi LZ and Wu XJ: Anti-inflammatory effect of Houttuynia cordata injection. J Ethnopharmacol 104: 245-249, 2006.

9. Miyata M,Koyama T and Yazawa K: Water extract of Houttuynia cordata Thunb. leaves exerts anti-obesity effects by inhibiting fatty acid and glycerol absorption. J Nutr Sci Vitaminol (Tokyo) 56: 150-156, 2010.

10. Hayashi K, Kamiya M and Hayashi T: Virucidal effects of the steam distillate from Houttuynia cordata and its components on HSV-1, influenza virus, and HIV. Plant Med 61: 237-241, 1995.

11. Chang JS, Chiang LC, Chen CC, Liu LT, Wang KC and Lin CC:Antileukemic activity of Bidens pilosa L. var. minor (Blume) Sherff and Houttuynia cordata Thunb. Am J Chin Med 29: 303-312, 2001.

12. Yang F, Ren L, Xiong Z, et al: Enterovirus 71 outbreak in the People's Republic of China in 2008. J Clin Microbiol 47: 2351-2352, 2009.

13. Chen X, Wang C, Xu L, et al: A laboratory evaluation of medicinal herbs used in China for the treatment of hand, foot, and mouth disease. Evid Based Complement Alternat Med 2013: 504563,2013

14. Lin TY, Liu YC, Jheng JR, Tsai HP, Jan JT, Wong WR and Horng JT: Anti-enterovirus 71 activity screening of Chinese herbs with anti-infection and inflammation activities. Am J Chin Med 37: 143-158, 2009.

15. Lau KM, Lee KM, Koon CM, et al: Immunomodulatory and anti-SARS activities of Houttuynia cordata. J Ethnopharmacology 118: 79-85, 2008.

16. Li S, Wang R, Zhang Y, Zhang X, Layon AJ, Li Y and Chen M: Symptom combinations associated with outcome and therapeutic effects in a cohort of cases with SARS. Am J Chin Med 34: 937-947, 2006.

17. Chen X, Wang Z, Yang Z, Wang J, Xu Y, Tan RX and Li E: Houttuynia cordata blocks HSV infection through inhibition of NF- $\kappa$ B activation. Antiviral Res 92: 341-345, 2011.

18. Liu G, Xiang H, Tang X, et al: Transcriptional and functional analysis shows sodium houttuyfonate-mediated inhibition of autolysis in Staphylococcus aureus. Molecules 16: 8848-8865, 2011.

19. Pan P, Wang YJ, Han L, Liu X, Zhao M and Yuan YF: Effects of sodium houttuyfonate on expression of NF- $\kappa$ B and MCP-1 in membranous glomerulonephritis. J Ethnopharmacology 131: 203-209, 2010.

20. Shin S, Joo SS, Jeon JH, et al: Anti-inflammatory effects of a Houttuynia cordata supercritical extract. J Vet Sci 11: 273-275, 2010.

21. Choy EH and Panayi GS: Cytokine pathways and joint inflammation in rheumatoid arthritis. N Engl J Med 344: 907-916, 2001.

22. Feldmann M: Development of anti-TNF therapy for rheumatoid arthritis. Nat Rev Immunol 2: 364-371, 2002.

23. Maini RN: Anti-TNF therapy from the bench to the clinic: a paradigm of translational research. Clin Med 10: 161-162, 2010.

24. Lee HJ, Seo HS, Kim GJ et al: Houttuynia cordata Thunb inhibits the production of pro-inflammatory cytokines through inhibition of the NFKB signaling pathway in HMC-1 human mast cells. Mol Med Rep 8: 731-736, 2013.

25. Maini RN and Taylor PC: Anti-cytokine therapy for rheumatoid arthritis. Annu Rev Med 51: 207-229, 2000. 
26. Chu K, Zheng H, Li H, Zhang Y, Zhang X, Xu W and Chen L: Shuangtengbitong tincture treatment of collagen-induced arthritis via downregulation of the expression of IL-6, IL-8, TNF- $\alpha$ and NF- $\kappa$ B. Exp Ther Med 5: 423-428, 2013.

27. Weinblatt ME, Keystone EC, Furst DE, et al: Adalimumab, a fully human anti-tumor necrosis factor alpha monoclonal antibody, for the treatment of rheumatoid arthritis in patients taking concomitant methotrexate: the ARMADA trial. Arthritis Rheum 48: 35-45, 2003.
28. Park E, Kum S, Wang C, Park SY, Kim BS and Schuller-Levis G: Anti-inflammatory activity of herbal medicines: inhibition of nitric oxide production and tumor necrosis factor-alpha secretion in an activated macrophage-like cell line. Am J Chin Med 33: 415-424, 2005. 